\title{
Core Depressive Symptoms In Depressed Cancer Outpatients
}

\author{
Pasquini Massimo*, Berardelli Isabella, Craba Ambra, Maraone Annalisa, Matteucci Gabriella, and \\ Biondi Massimo
}

Department of Neurology and Psychiatry, Psycho-oncology Unit, Rome, Italy

\begin{abstract}
Objective: This study aimed to estimate the prevalence of core depressive symptoms among cancer outpatients diagnosed with depressive or adjustment disorders with depressed mood. We also aimed to detect potential differences between patient self-assessment and psychiatrist evaluation in classifying the severity of depression.

Methods: Fifty-two outpatients diagnosed with solid tumor malignancy and depressive or adjustment disorder with depressed mood were assessed using the Hamilton Depression Rating Scale (HAMD-17) (and its shortened version the HAMD-7) and the Zung Self-Rating Depression Scale (ZSDS) (and its shortened version BZSDS).

Results: Based on HAMD-7 results, the prevalence of moderate depression was low (7.7\%); using the BZSDS moderate depression was absent. Mild depression was identified in $82.3 \%$ and $73 \%$ of our subjects using the HAMD-7 and the BZSDS, respectively. The strength of agreement between psychiatrist and patients' self-evaluation for mild depression was "slight", employing the original and the abbreviated versions of both scales.

Conclusion: Our findings suggest that the prevalence of core depressive symptoms is very low in cancer patients diagnosed with depressive disorder. The lack of a strong agreement between psychiatrist and patient in classifying the severity of depression highlights the importance of factors such as well-being and functional status among depressed cancer patients in their self assessment of depression.
\end{abstract}

Keywords: Cancer, Depressive Disorders, BZSDS, HAMD-7, Core depressive symptoms.

\section{INTRODUCTION}

The reported prevalence of major depression among cancer patients is highly variable [1]; this variation can be attributed to differences in study populations, procedures, instruments, observers, and patient variables. In addition, nosological classification is unhelpful to clinicians and researchers in diagnosing depressive disorders in subjects with medical illness. Assessing depression symptoms in cancer patients often involves differentiating between a depressive disorder and an adjustment disorder with depressive mood. Adjustment disorder with depressive mood is linked to a specific triggering occurence and places itself in a transitional zone on the continuum of distress between normative adaptation and a psychiatric disorder. As a consequence, adjustment disorders are frequently addressed in depressed cancer patients as an "afterthought" [2]. Furthermore, an epidemiological study failed to distinguish between adjustment disorders and depressive episode [3]. In order to evaluate the severity of depression in cancer patients it is necessary to adopt an approach that discriminate the somatic symptoms of cancer from those due to treatment from the criteria of DSM-IV for major depression. The proposed "exclusive approach" [4] to the diagnosis of major depression in this population may increase the specificity of the diagnosis.

*Address correspondence to this author at the Department of Neurology and Psychiatry, "SAPIENZA" University of Rome, Viale dell'Universita` 30, Rome 00185, Italy; Tel: 06 49914591; Fax: 06 4454765;

E-mail: massimo.pasquini@uniroma1.it.
This approach excludes somatic symptoms of depression, such as fatigue, weight loss, loss of appetite or sleep disruption from the nuclear depressive symptoms. The presence of core depressive symptoms, that comprise excessive or inappropriate guilt, sense of failure, dissatisfaction and selfdislike, among cancer patients has been previously investigated [5]. In spite of the crucial importance of other symptoms in depressed cancer patients assessing specifically typical depressive symptoms among these subjects might improve clinical management.

Moreover, apart from physicians' judgment, understanding patients' concerns and appraisal of their depressive conditions is an essential issue in assessing depression. This aspect is of particular importance in psycho-oncology, when the clinical situations are equivocal and the evidence-based decision-making process become difficult.

The main goal of the present study was to assess the presence of core depressive symptoms among cancer outpatients previously diagnosed with depressive or adjustment disorders with depressed mood. An additional aim was to detect potential differences between self-perceived mental status and the psychiatrist assessment.

\section{METHODS}

\section{Design}

This was an observational study carried out at the Psycho-oncology Unit of the Department of Neurology and Psy- 
Table 1. Patient Characteristics

\begin{tabular}{|c|c|}
\hline $\mathbf{N}$ & 52 \\
\hline AGE, YEARS, MEAN (SD) & $54.63 \pm 11.3$ \\
\hline GENDER, M/F & $\begin{array}{l}\text { M } 14(26.9 \%) \\
\text { F } 38(73.1 \%)\end{array}$ \\
\hline $\begin{array}{c}\text { MARITAL STATUS, } \\
\text { N (\%) }\end{array}$ & $\begin{array}{c}\text { Single } 5(9.6 \%) \\
\text { Married } 35(67.3 \%) \\
\text { Separate/Divorced 6(11.5\%) } \\
\text { Widowed 6 }(11.5 \%)\end{array}$ \\
\hline $\begin{array}{c}\text { EDUCATIONAL STATUS, } \\
\mathrm{N}(\%)\end{array}$ & $\begin{array}{c}\text { Primary School } 8(15,4 \%) \\
\text { Middle School } 16(30.8 \%) \\
\text { Graduate } 19(36.5 \%) \\
\text { Degree } 9(17.3 \%)\end{array}$ \\
\hline $\begin{array}{l}\text { OCCUPATION, } \\
\text { N }(\%)\end{array}$ & $\begin{array}{c}\text { Retired } 15(28.8 \%) \\
\text { Employee } 16(30.8 \%) \\
\text { Privately employed } 7(13.5 \%) \\
\text { Not working } 3(5.8 \%) \\
\text { Housewife } 8(15.4 \%) \\
\text { Other } 3(5.8 \%)\end{array}$ \\
\hline $\begin{array}{l}\text { TIME SINCE CANCER } \\
\text { DIAGNOSIS (MONTHS) }\end{array}$ & N (\%) \\
\hline 0-3 MONTHS & $10(19.2 \%)$ \\
\hline 3-6 MONTHS & $7(13.5 \%)$ \\
\hline 6-12 MONTHS & $10(19.2 \%)$ \\
\hline 12-24 MONTHS & $8(15.4 \%)$ \\
\hline MORE THAN 24 MONTHS & $17(32.7 \%)$ \\
\hline STAGE & $\mathrm{N}(\%)$ \\
\hline 0 & $3(5.8 \%)$ \\
\hline I & $7(13.5 \%)$ \\
\hline II & $12(23.1 \%)$ \\
\hline III & $13(25.0 \%)$ \\
\hline IV & $17(32.7 \%)$ \\
\hline CANCER LOCATION & $\mathrm{N}(\%)$ \\
\hline BREAST & $26(50.0 \%)$ \\
\hline PROSTATE & $4(7.7 \%)$ \\
\hline $\begin{array}{c}\text { GASTROINTESTINAL } \\
\text { TRACT }\end{array}$ & $7(13.5 \%)$ \\
\hline STOMACH & $1(1.9 \%)$ \\
\hline LUNG & $5(9.6 \%)$ \\
\hline OVARY & $3(5.8 \%)$ \\
\hline OTHER & $6(11.5 \%)$ \\
\hline TREATMENT TYPE & $\mathrm{Y} / \mathrm{N}(\%)$ \\
\hline SURGERY & $\begin{array}{l}\text { Yes } 46(88.5 \%) \\
\text { No } 6(11.5 \%)\end{array}$ \\
\hline CHEMOTHERAPY & $\begin{array}{l}\text { Yes } 37(71.2 \%) \\
\text { No } 15(28.8 \%)\end{array}$ \\
\hline RADIATION & $\begin{array}{l}\text { Yes } 20(38.5 \%) \\
\text { No } 32(61.5 \%)\end{array}$ \\
\hline
\end{tabular}

chiatry of the SAPIENZA University of Rome, between February 2009 and February 2010.

\section{Patients}

One rater (MP) assessed outpatients consecutively referred by two different oncology divisions. Inclusion criteria were: age $>18$ years, a diagnosis of cancer within the previous five years, and a current diagnosis of depressive disorder (major depressive disorders and dysthymia) or adjustment disorders with depressed mood according to the DSM-IV criteria. Exclusion criteria were: presence of a neurological disorder or cerebral metastases, presence of comorbid psychiatric diagnosis, bipolar disorder, or exposure to psychotropic drugs in the preceding month. Approval from the Hospital Ethical Committees and written informed consent from participants were obtained.

\section{Assessment}

Study assessments were done at the Psycho-oncology Unit during the first visit. All patients were given the selfadministered Zung Self Depressive Scale in the waiting room. All patients were diagnosed according to DSM-IV criteria and blindly assessed by the principal investigator (M.P.), who was the only rater in this study. The HAMD-17 was used to assess the severity of depression. The brief versions, HAMD-7 and BZSDS [6, 7], were employed to detect melancholic symptoms. The HAMD-7 and the BZSDS both focus on the core depressive symptoms of depression, minimizing the anxiety or somatic items. The BZSDS is a 11version of the well-known ZSDS that limits the somatic items. Psychometrics properties were previously studied for both instruments $[6,7]$. In order to assess the severity of core depressive symptoms we employed the suggested cut-off scores for the HAMD-7 (0-3 Normal, 4-12: mild, 13-20: moderate, >20: severe) and for the BZSDS (11-21 Normal, 22-32: mild, 33-38: moderate, 39-44: severe). We also used the suggested cut off scores for the HAMD-17 ( $<7$ : normal, 8-17: mild, 18-24: moderate, $\geq 25$ : severe) and for the ZSDS (20-39: normal, 40-47: mild, 48-55: moderate, 56-80: severe).

\section{Statistical Analysis}

We described the frequency distribution of all variables of interest, and estimated their prevalence and 95\% confidence intervals. Scores on the HAMD-7 and the BZSDS were classified according to the above mentioned severity criteria. Specificity, sensitivity, positive predictive value, and negative predictive value for ZSDS and BZSDS were calculated. Degree of agreement between patients and psychiatrist were assessed by Cohen's kappa. SPSS for Windows, version 13.0 was used for all analyses.

\section{Results}

Of the 63 patients invited to participate, $52(82 \%)$ were enrolled in the study; 11 were not eligible because of their psychiatric diagnoses. Socio-demographic and clinical characteristics are shown in Table 1. The majority of the subjects were classified as suffering from an adjustment disorder with depressed mood (63.5\%); major depressive disorder and dysthymia were diagnosed in $28.9 \%$ and $7.6 \%$ of patients, respectively (Table 2). Severe depressive symptoms were absent according to HAMD-7, HAMD-17 and BZSDS while using the ZSDS, $38.5 \%$ of patients were classified as having severe depression. Point estimates of core symptoms prevalences and 95\% confidence intervals limits are shown in Table 3. 
Table 2. Psychiatric Diagnoses and Scores on Measures for Depression Severity

\begin{tabular}{|c|c|}
\hline $\begin{array}{c}\text { ADJUSTMENT DISORDERS WITH } \\
\text { DEPRESSED MOOD }\end{array}$ & $\mathbf{3 3}(\mathbf{6 3 . 5 \% )}$ \\
\hline \hline DYSTHYMIA & $4(7.6 \%)$ \\
\hline MAJOR DEPRESSIVE DISORDER & $15(28.9 \%)$ \\
\hline & Mean (S.D.) \\
\hline HAM-D 17 & $12.9 \pm 6$ \\
\hline HAM-D 7 & $7.06 \pm 3.2$ \\
\hline ZSDS & $51.1 \pm 9$ \\
\hline BZSDS & $23 \pm 4.5$ \\
\hline
\end{tabular}

\section{Results According to the HAMD-7 and BZSDS}

Mean scores observed for HAMD-7 and BZSDS were $7.06 \pm 3.4$ and $23 \pm 4.5$, respectively, indicating mild depression (Table 2). Out of 52 study subjects, only $7.7 \%$ were classified as moderately depressed according to the HAMD7, whereas no patient we found to be moderately depressed according to the BZSDS. Using the HAMD-7, 82.3\% were classified with mild depression; $73 \%$ were found to have mild depression according to the BZSDS. Assuming the HAMD-7 as the gold standard, sensitivity, specificity, positive predictive value, and negative predictive value of the BZSDS in classifying mild depression were $76.6 \%, 44 \%$, $86.8 \%$, and $28.5 \%$, respectively. The strength of agreement between psychiatrist (HAMD-7) and patients' (BZSDZ) evaluation for the presence of mild depression was "slight" ( $71 \%$ agreement; kappa $=0.173$ with $95 \%$ CI 0.567 to 0.824 ) [8].

\section{Results According to the HAMD-17 and ZSDS}

Mean scores observed for HAMD-17 and ZSDS were $13 \pm 5.92$ and $51.7 \pm 8.91$, respectively. According to the HAMD-17 the prevalence of moderate depression was $13.5 \%$; with the ZSDS the prevalence of moderate depression was $34.6 \%$. Using the HAMD-17, $75 \%$ of patients were classified as having mild depression; ZSDS classified $11.5 \%$ of patients as having mild depression. Twenty patients $(38.5 \%)$ were classified as severe depressed according to the ZSDS. According to HAM-17, $11.5 \%$ of patients obtained a score $<7$. Assuming the HAMD-17 as the gold standard, sensitivity, specificity, positive predictive value, and negative predictive value of the ZSDS in classifying mild depression were $12.8 \%, 92.3 \%, 83.3 \%$, and $26.1 \%$, respectively. The strength of agreement between psychiatrist (HAMD-17) and patients (ZSDS) evaluation for the presence of mild depression was "slight" (32\% agreement; kappa $=0,028$ with 95\% CI 0.20 to 0.47 ).

\section{DISCUSSION}

In our sample of depressed cancer patients, core depressive symptoms were present in a minority of them. Feelings of guilt and suicide ideation were present respectively in $23 \%$ and $9.6 \%$ of participants. Whereas interest, pleasure and level of activities was detected in $92 \%$ of patients. This latter finding might be overestimated because physical or mental fatigue are often related to cancer therapies. The prevalence
Table 3. Prevalence rate of Symptoms According to the HAMD-7

\begin{tabular}{|c|c|c|}
\hline & Prevalence & Confidence Intervals \\
\hline \hline Depressive Mood & $96 \%$ & $0.87-0.98$ \\
\hline Feelings of Guilt & $23 \%$ & $0.13-0.36$ \\
\hline Work and activities & $92 \%$ & $0.81-0.96$ \\
\hline Suicide & $9.6 \%$ & $0.42-0.20$ \\
\hline Psychological anxiety & $94 \%$ & $0.84-0.97$ \\
\hline Somatic Anxiety & $50 \%$ & $0.36-0.62$ \\
\hline Somatic Symptoms & $52 \%$ & $0.38-0.64$ \\
\hline
\end{tabular}

of moderate depression was low (7.7\%) for the HAMD-7, while no patient was found to have moderate depression according to the BZSDS. Mild depression was identified using HAMD-7 and BZSDS in $82.3 \%$ and $73 \%$ of participants, respectively. As expected, employing the HAMD-17 and the ZSDS detected a higher rate of moderate depression, because these scales include somatic symptoms, which could also be attributable to cancer or medications. These results stress the importance of using appropriate tools for the assessment of core depressive symptoms in cancer patients. From a pragmatic point of view, however, the severity of depression, or the presence of nuclear depressive symptoms, should not be considered a unique indicator for intervention, as we know that antidepressants and psychotherapies for sub-threshold depression, anxiety, and other conditions such as hot flashes or pain in cancer patients are appropriate and effective. Nevertheless, the assessment of depression as such might improve therapeutic decision-making, in terms of medication dosage and length of treatment. The high rate of mild depression found in our study is attributable to the high prevalence of adjustment disorders with depressed mood (63\%) among our study subjects, since, as already reported, the distribution of depression severity does not differ between adjustment disorders and depressive disorders [3]. Since the BZSDS detected no cases of moderate depression, we restricted our considerations to mild depression. Given the high prevalence of mild depression in our sample, the positive predicting value of the BZSDS is high $(86.8 \%)$, and the negative predictive value is quite low $(28.5 \%)$. This observation suggests that, in similar settings, excluding the presence of mild depression on the basis of BZSDS alone leads to a false positive rate as high as $71.5 \%$. Another purpose of our study was to assess the degree of agreement between psychiatrist and patients concerning the severity of depression. Overall, the results of this study suggest a "slight" agreement, which in our opinion is unsatisfactory, for both the shortened versions and the original versions of the scales. The latter, which includes somatic symptoms, is an application of the "inclusive approach" for discriminating somatic symptoms of cancer [4]. On this basis we speculate that patients' perspective of their own depressive status incorporates features other than depressive symptoms, such as the impairment of their general sense of well-being or functional status $[9,10]$ These factors might explain the lack of a strong agreement between patients and psychiatrist. This observation is useful in that it reflects actual clinical practice. This study have several limitations. The main limitation of our 
study is sample size; a larger sample would improve the precision of the estimates. In addition, accuracy of diagnosis may be decreased due to the choice to employ the DSM-IV criteria rather than the SCID-I. Another limitation is the external validity of our results, since the overrepresentation of breast cancer in our sample limits the generalizability of our inferences.

\section{CONFLICT OF INTEREST}

None.

\section{REFERENCES}

[1] Massie MJ. Prevalence of depression in patients with cancer. J Natl Cancer Inst Monogr 2004; 32: 57.

[2] Casey P. The 'afterthought' diagnosis: rehabilitating adjustment disorders. Expert Rev Neurother 2006; 6: 145-51.

[3] Casey P, Maracy M, Kelly BD et al. Can adjustment disorder and depressive episode be distinguished? Results from ODIN. J Affect Disord 2006; 92: 291-7.
[4] Bailey RK, Geyen DJ, Scott-Gurnell K, Hipolito MMS, Bailey TA, Beal JM. Understanding and treating depression among cancer patients. Int J Gynecol Cancer 2005; 15: 203-8.

[5] Pasquini M, Speca A, Mastroeni S, Delle Chiaie R, Sternberg CN, Biondi M. Differences in depressive thoughts between major depressive disorder, IFN- $\alpha$ induced depression and depressive disorders among cancer patients. J Psychosom Res 2008; 65: 153-156.

[6] Passik SD, Kirsh KL, Donaghy KB, et al. An attempt to employ the Zung Self-Rating Depression Scale as a "lab test" to trigger followup in ambulatory oncology clinics: criterion validity and detection. J Pain Symptom Manage 2001; 21(4): 273-81.

[7] McIntyre RS, Konarski JZ, Mancini DA, et al. Measuring the severity of depression and remission in primary care: validation of the HAMD-7 scale. CMAJ 2005; 22: 173(11): 1327-34.

[8] Landis RJ, Koch GG. The measurement of observer agreement for categorical data. Biometrics 1977; 33:154-74.

[9] Kleiboer A, Bennett F, Hodges L, Walker J, Thekkumpurath P, Sharpe M. The problems reported by cancer patients with major depression. Psychooncology 2011; 20(1): 62-8.

[10] Mangelli L, Fava GA, Grandi S, et al. Assessing demoralization and depression in the setting of medical disease. J Clin Psychiatry 200; 66(3): 391-4.

Received: April 28, 2011

(C) Massimo et al.; Licensee Bentham Open.

This is an open access article licensed under the terms of the Creative Commons Attribution Non-Commercial License (http://creativecommons.org/licenses/by-nc/3.0/) which permits unrestricted, non-commercial use, distribution and reproduction in any medium, provided the work is properly cited. 